\title{
Web Science: Expanding the Notion of Computer Science
}

\author{
Su White \\ Electronics and Computer Science \\ University of Southampton \\ UK \\ +442380594471 \\ saw@ecs.soton.ac.uk
}

\author{
Michalis N Vafopoulos \\ Aristotle University of Thessaloniki \\ Thessaloniki \\ Greece \\ +302310383619 \\ vaf@aegean.gr
}

\begin{abstract}
This paper discusses the role and place of Web Science in the computing disciplines. It provides an account of work which has been established towards defining an initial curriculum for Web Science. It presents and analyses plans for future curriculum developments utilizing novel methods to support and elaborate curriculum definition and review. The findings of a desk survey of Web Science education are presented. The paper then recommends future activities which may help determine whether we should expand the notion of computer science.
\end{abstract}

\section{Categories and Subject Descriptors}

K.3.2 [Computers and Education]: Computer and Information Science Education - Computer Science Education, Curriculum.

\section{General Terms}

Documentation, Design, Human Factors, Standardization.

\section{Keywords}

Co-creation, Co-evolution, Computing Curriculum, Educational Repository, Inter-disciplinarity, Negotiated Curriculum, Web Science Curriculum, Web Science Education.

\section{INTRODUCTION}

This paper considers what place Web Science might occupy within the family of the computing disciplines. Initially defined as "the science of decentralized information systems", the coherent case for Web Science as a discipline is presented by Berners-Lee et al in 2006 [7, 8]. Having established itself as a rapidly evolving and fundamentally interdisciplinary field of study [13, 20] explorations and discussions of the relationship between Web Science and computer science have been initiated [14, 17, 21].

Since 2006 a series of curriculum development workshops have taken place and a number of institutions have begun to teach Web Science at masters and undergraduate level. Postgraduate Summer Schools have been organized and seminar series established. Perspectives and understandings of Web Science have also been integrated into established courses, typically as a perspective which demonstrates current theoretical advances and furnishes examples of contemporary practice. A Web Science curriculum categorization exercise has been undertaken [24, 25] (Table 1) and collaborations have been formed to define and agree a Web Science curriculum [26].

\footnotetext{
Permission to make digital or hard copies of all or part of this work for personal or classroom use is granted without fee provided that copies are not made or distributed for profit or commercial advantage and that copies bear this notice and the full citation on the first page. To copy otherwise, or republish, to post on servers or to redistribute to lists, requires prior specific permission and/or a fee.

SIGCSE'12, February 29-March 3, 2012, Raleigh, North Carolina, USA Copyright 2012 ACM 978-1-4503-1098-7/12/02...\$10.00.
}

The practice of established computing disciplines is to define and evolve subject definitions as formal recommendations for model curricula. Typically published by professional bodies like the $\mathrm{ACM}$, these provide definitions of the aims and objectives of their curricula. Content is influenced by reflections, public discussion, and the de-facto realization of programs of study across universities and colleges worldwide. Faculty regularly report insights to communities like SIGCSE on changes whose impact ranges across individual topic areas, whole courses and programs.

The rest of this paper tracks the emergence of Web Science. It presents an account of a preliminary definition of the Web Science body of knowledge and associated curriculum initiatives. It considers the background to recent changes in the ACM curriculum family. It compares the emerging Web Science curricula with the various computing curricula to provide evidence to take this discussion further.

Questions necessarily arise: is it true, as Shneiderman claims in The Communications of the ACM [21], that Web Science signals a whole new way of thinking about computer science? Does Web Science have any chance of being recognized, when, as Hendler et al. point out [14], its only place in the ACM taxonomy is under 'miscellaneous'? Can communities like SIGCSE agree a place for Web Science in existing curricula, either as a specialism or in its own right? Is it time to expand our notions of computer science?

\section{WHAT IS WEB SCIENCE?}

Web Science as a coherent area of study was brought formally to academic and public attention in 2006 with publications [7, 8] and the official launch of the Web Science Research Initiative. Today the formal Web Science agenda is driven through the Web Science Trust and the annual Web Science conference which since 2011 has been formally supported by the ACM. Web Science incorporates the quest to build an organized body of knowledge which can help make sense of the Web in an increasingly connected world. It is the study of an engineered technology (the Web) and the inter-related impacts of that technology on human, social and organizational domains. The study of Web Science is fundamentally interdisciplinary since it incorporates enquiring into what constitutes the Web, alongside how and why practices and organizations have emerged from, or are modified by, the wider interaction of society with the Web. As Berners-Lee et al point out in their 2006 monograph 'A Framework for Web Science" [8], Web Science, like computer science, is partly analytic but also synthetic.

It must be emphasized that Web Science is much more than the study of web technologies. The web ecosystem in its own right forms an important and coherent area of study. Web Science is of particular interest to members of the computing disciplines because it is in many ways like information science; it brings together science, technology and engineering with social, human and organizational sciences. However, we observe Web Scientists 
practicing in many different established disciplines. Some have originated in the computing disciplines others are found in independent disciplines utilizing their computing-related insights, expertise or perspective as core part of their subject specialism.

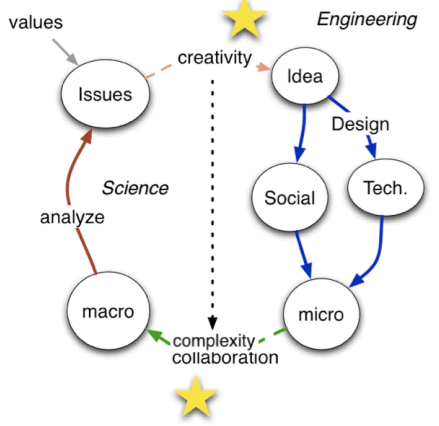

Figure 1. Berners-Lee's science and engineering approach with magic [5] modified to show complexity and collaboration

The complexity and inter-disciplinarity of Web Science has been represented by Berners-Lee as a process in which social and engineering factors are both present [5, 8]. This was first described by Berners-Lee et al and then subsequently developed into graphical form (figure 1). The inter-disciplinarity of Web Science has been the subject of ongoing discussion [13, 14, 20]. It is manifested in the range of perspectives presented in papers at the Web Science conference, and in the variety of different viewpoints and specialisms which are observed in the various Web Science programs of study which are underway and represented at the annual Web Science curriculum workshop. Embracing inter-disciplinarity presents particular problems for course designers; discussed below and in subsequent sections.

Hendler et al. in their 2008 CACM paper 'Web Science an Interdisciplinary Approach' opened the discussion on the place of Web Science in relationship to computer science [14]. They point out that the constraints of the ACM taxonomy reduces web scientists who research and publish in the computing disciplines to categorizing their work as 'miscellaneous'. They point out this is despite the fact that the Web is: "the most used and one of the most transformative applications in the history of computing, even of human communications. It has changed how those in academia teach, communicate, publish, and do research. In industry, it has not only created an entire sector (or, arguably, multiple sectors) but affected the communications and delivery of services across the entire industrial spectrum. In government, it has changed not only the nature of how governments communicate with their citizens but also how these populations communicate".

In Sections 3, the extent of Web Science in the curriculum is identified and analyzed. The details have been consolidated from a survey (https://www.isurvey.soton.ac.uk/2290) conducted in the spring of 2011, Web Science Curriculum workshop discussion and individual enquiry. Section 4 presents the findings of a desk survey which compares the development of the current ACM curriculum family with the emergence the Web Science field of study and associated developments towards establishing an agreed Web Science curriculum. It examines example programs and courses, and identifies current views on the broader issues of curriculum definition. The final section considers how Web Science might therefore impact computer science and the family of computing disciplines.

\section{WEB SCIENCE IN THE CURRICULUM}

Currently there are approximately 20 Web Science courses worldwide with the majority at postgraduate level. Only a few undergraduate programs exist; more are emerging. Web Science courses are however sometimes offered as electives or as additional specialisms outside the mainstream curriculum. Although not exhaustive, the Web Science Trust maintains a list of taught programs demonstrating different ways in which Web Science can be nuanced (http://webscience.org/study.html).

\subsection{The Web Science Curriculum}

Since its inception, the Web Science Research Initiative and subsequently the Web Science Trust have convened annual workshops to discuss the contents and the formal definition of the Web Science Curriculum. Institutions who have been early in developing and offering programs of study in Web Science have pooled their expertise. One outcome has been the definition of a Web Science Subject Categorization (WSSC). This work was initially developed via a wiki hosted by the Web Science Trust. During 2011 it became available for public access (http://webscience.org/2010/wssc.html). The categorization can be applied to academic publications in Web Science, but a core part can also be used to define the boundaries of the Web Science body of knowledge. It is of particular use as a step towards curriculum definition. Working predominantly from existing definitions used by the World Wide Web Conference (W3C) and Web Science Conference a team of collaborators led by Michalis Vafopoulos created a framework for Web Science Subject Categorization [24, 25]. The definitions are linked to matching categories in computing, mathematics, economics sociology and political sciences. Table 1 , at the end of the paper presents an abridged version.

Underpinning the Web Science Subject Categorization, is a model of the Web as an application that runs on the Internet the successful technical progress of which is crucial to the Web's universal role. It is vital for innovation that the Internet and the Web work together but advance independently [6]. Readers reviewing the subject categorization will recognize topics which also belong within the curriculum of their specialist area. The topic headings may equate to whole courses or form part of the contemporary understanding of the specialism. However it is also clear that the topics are all part of an individual whole which incorporates the particular multi-disciplinary and interdisciplinary perspectives which are essential to Web Science.

Category (A) categorizes publications concerned with instructional and research exposition, conference proceedings and collections of papers. It is not directly relevant to the teaching body of knowledge - although teaching and research methods do have a role; see section 5 . The web history and methodology category (B) includes web history, related biographies and epistemological and theoretical models of the web as an artifact. The Web Technologies (C) category addresses the underlying infrastructure (web milieux and basic web architecture) and the major enabling technologies for each Web era, namely Web 2.0, Semantic Web/Linked Data and Web of Things. Much of the debate within the Web Science curriculum community has focused on understanding the differences between a technologically-led perspective and a more interdisciplinary unified approach which is claimed for Web Science. Another area of contemporary interest concerns the class of scale-free networks. This area, massively analyzed and used in various disciplines and applications during the last five years, was initially identified through the analysis of real data gathered from Internet and Web 
networks [4]. The web analysis category (D) covers the mathematical methods applied in analyzing and exploring the Web. The web society category (E) covers topics which represent a range of human, social and organizational science perspectives: economic and business analysis; social engagement and social science; personal engagement and psychology; philosophy; law and politics and governance. This category reflects currently dominant associated specialisms and will inevitably change and evolve. It is also the area which institutions will use most selectively reflecting the expertise of departments and faculty who are hosting and leading specific teaching programs.

Like computer science teachers, Web Science teachers are developing expertise and understandings about effective ways in which to communicate the nuances of the discipline to learners, especially when seeking to explain the ways in which Web Science is distinctive from the study of web technologies. Specifically, the study of the Web and philosophy has been emerged in the framework of the PhiloWeb series of conferences (http://web-and-philosophy.org/). Initial definitions encompassing existence, time and space in the web may become particularly useful in building the principles of web didactics. These factors impact on Teaching the Web, category (F) covers knowledge related to educational approaches for Web Science at pre-college, undergraduate and graduate levels.

\subsection{Web Science Teaching Today}

In order to extend and refine our understanding of the extent and nature of Web Science education, a brief survey across the Web Science community (https://www.isurvey.soton.ac.uk/2290) was conducted. Ten respondents rated teaching practices against the Web Science Subject Categorization (WSSC) shown in Table 1. For the purposes of the survey, categories A (general) and F (teaching) were excluded although it is recognized that both are relevant to broader discussions of the curriculum. Interim analysis of the responses to the survey were reported to the $2011 \mathrm{Web}$ Science conference [26]. The survey used the WSCC as a starting point for the body of knowledge. Responses largely confirmed a good match with interests and concerns of established teaching programs. Inevitably linguistic differences mean that detail of such understanding is best agreed via face-to-face conversations such as workshop and committee discussions. Since that time the number of respondents has increased, and the findings have remained broadly consistent. We will continue to gather this data from different communities worldwide, adjusting questions slightly to reflect particular understandings or teaching approaches which predominate in different education systems.

Listed programs at undergraduate and masters level are run in Europe and the United States, although it is known that universities in Brazil, Pakistan, Korea and China are also actively teaching Web Science. Undergraduate programs are typically hosted in institutions where a number of faculty have established research in Web Science and thus, there also exists an established stream of postgraduate research students in the area. Furthermore many teachers are already integrating Web Science perspectives into the established software engineering, computer science, information technology and information science curriculum as they incorporate current examples and emerging ideas. There is also evidence that students, at postgraduate and undergraduate level, introduce Web Science into their studies by choosing project and dissertation topics which fall within Web Science.

\subsection{An example of a Web Science Program}

Figure 2 shows an example structure of a Web Science masters program taught in Southampton. The program has now been taught for three years to a small cohort $(\sim 20)$. Students begin with a broad range of prior experience across science, technology and the human and social sciences, around $25 \%$ are CS graduates. UK students specialize from their first year of undergraduate study. The program has attracted approximately $50 \%$ female students (compared to around $10 \%$ in $\mathrm{CS}$ ). The educational approach reflects the view that the web is a technical engineered artifact which is co-created and co-evolves. The course is highly participative using the students' prior experience as a resource to enable each participant to develop their own but shared understanding of the interdisciplinary nature of the web. It incorporated activities and resources which are co-created.

An undergraduate degree in Web Science is planned but it is unlikely to differ radically from this basic structure. There are differences between US and European educational systems which might affect such implementations. The program shown has been developed over four years, and is now teaching its third cohort. The team of faculty who designed the course, and who now teach the modules, purposefully included Web Scientists who are not computer scientists and there is active input from an industrial advisory panel. Content has been revised, reorganized and restructured in light of feedback from increasingly multidisciplinary cohorts of students. Although visualized as a progression, apart from the capstone experience all components of the program are present as threads running through the taught sessions delivered over two consecutive semesters.

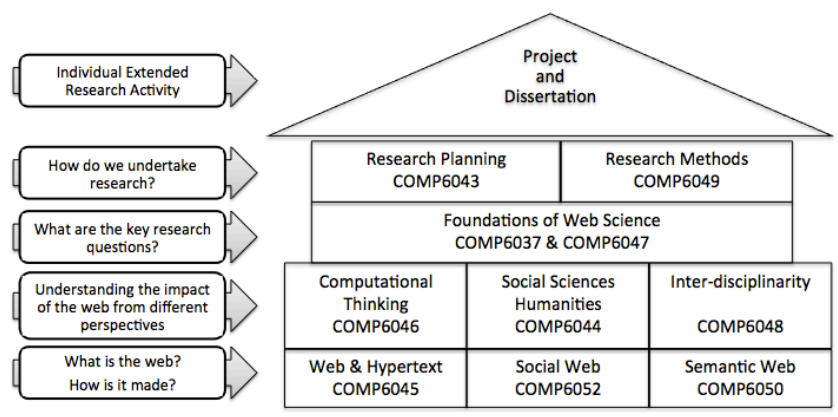

Figure 2 example of course content and approach

The diagram incorporates an acknowledgement of the need for interdisciplinary underpinnings to themselves support the foundations of Web Science. Research methods are emphasized for a number of reasons. i) Web scientists work at the frontiers of knowledge and understanding so research skills are relevant to every possible outcome in terms of career progression; ii) It ensures that the teaching moves beyond the simple descriptive and theoretical, enabling the students to experience inter-disciplinarity rather than encountering it as a static concept; iii) Research activities provide an authentic vehicle of the critical and analytical thinking, communication, interpersonal and team skills.

The masters attracts a mix of home and international students. We offer both Web Science and Web Technology (see flow diagram at http://webscience.ecs.soton.ac.uk). International students overwhelmingly opt for web technology; a subject known and understood in their home countries, although some ambitious international students who intend to progress to $\mathrm{PhD}$ have chosen Web Science. The web technology program takes a strong technological/software engineering approach, and only one module (Hypertext and Web Technologies for Masters) is common across the two programs. Currently Web Science students normally progress to $\mathrm{PhD}$ studentships, but our industrial panel represents a wide range of companies, suggesting that future 
work destinations will incorporate specialist consultancies alongside names already familiar from business and IT.

\section{THE ACM CURRICULUM FAMILY}

It is widely acknowledged that the focus and curriculum content in the family of computing disciplines is constantly evolving. External change inevitably triggers educational and curricula responses. Occasionally, when the disjunction becomes large, individual institutions undertake wholesale revision such as the recent changes at Stanford which Sahami et al. report in their 2010 paper [18]. The SIGCSE community provides a forum for sharing innovations, consolidating learning across our community of practice and providing additional communication channels between faculty and professional bodies.

The ACM has established a systematic program which draws on expertise from across the community and works to consolidate the learning into a coherent form manifested as formal models of various different recommended curricula $[1,2,12,15,22]$. Preparation for the Computing Curricula 2013 is now underway [19] which it is intended will build on previous model curricula $[2,3]$. The rolling program of revisions demands time and effort, but it is a necessary response to the reality of our discipline areas. The nature of this overhead was emphasized in 2011 when the ACM/IEEE Task Force reported to SIGCSE "The development of curricular guidelines in computer science is particularly challenging given the rapid evolution and expansion of the field. Moreover, the growing diversity of topics in computer science and the integration of computing with other disciplines create additional challenges and opportunities in defining computing curricula" [19]

The ACM has sought to define curriculum recommendations since the 1960s and recognizes the diversity of computing disciplines with its 2005 overview volume [1]. It establishes its rationale in its opening words: "Computing has dramatically influenced progress in science, engineering, business, and many other areas of human endeavor. In today's world, nearly everyone needs to use computers, and many will want to study computing in some form". It identifies a family of disciplines which may grow or change in time (figure 3). CC2005 anticipates that other curriculum volumes would be needed for emerging disciplines.

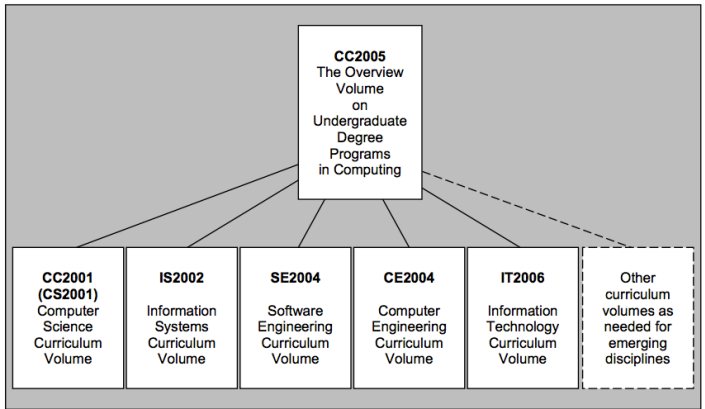

Figure 3. CC2005: the family of computing disciplines [1]

\subsection{Web Science In The Curricula}

A review of computing curriculum 2005 and specialist curricula within the computing family was undertaken. CC2005 provided the starting point. Subsequently specific model curricula were examined (figure 3), computer engineering and software engineering models, deemed most distant from Web Science, were excluded leaving computer science [2], information technology [15] and information science $[12,22]$. The comparison items were course areas, topics and specific bodies of knowledge.
Examining the computing problem space in CC2005, p16 [1] confirmed that Web Science could have a place in the family. Topic areas for the computing family are identified as Organizational Issues and Information Spaces; Applications Technologies; Software Methods and Technologies; Systems Infrastructure; and Computer Hardware and Architecture. Of the 17 specific relevant non-computing topics identified in CC2005, 12 were deemed to also be part of Web Science, overlapping directly with IT and IS. When considering computing topics the pattern was repeated, of the 40 potential topics, 37 were deemed relevant to Web Science, again consistent with IT and IS. Next, specific model curricula all published at later dates, were examined.

- In IT2006 nine of the 13 Body of Knowledge (BOK) items map to Web Science, of the remainder there is some overlap (equivalent to approximately $75 \%$ of the suggested hours).

- In CS2008 looking at the core, only three of the 14 areas had near complete overlap, however many of the others are to be found in parts in the WSSC.

- In IS2010 four of the seven topic areas in Information Systems Specific knowledge were deemed relevant to Web Science, with overlap in the remaining areas. All of the computer areas identified were consistent with Web Science.

- MSIS2006 looked at masters degrees. It defined constituent courses rather than a body of knowledge. All of the courses had overlap with Web Science, but the focus was different, suggesting, like IT an overlap of more than $50 \%$

New concepts introduced into MSIS2006 (business processes; emerging technologies; globalization; human computer interactions; and the impacts of digitization) were all considered relevant to Web Science. Similarly all items in the list of recent advances itemized by IT2008 were considered to be at the core of Web Science. Besides the overlap, there is a large part of the WSSC which is not found in any computing family curricula.

Little previous work exists discussing the role of Web Science in the computing curriculum. Riera's 2009 Web Science conference paper argues for Web Science to be added to the family of computer-related curriculum [17]. Riera presents four distinct focus area though which the computing curricula has progressed, each of which persists today; the computer systems; computer networks; web technologies and 'webiety' i.e. web[soc]iety. The paper argues that each member of the family of computing disciplines occupied a different space across these focus area, and Web Science should occupy the next space.

The sustained emergence of new methods and tools, never mind the interdisciplinary science of the web also challenge the traditional methods with which we define and publish model curricula. Community approaches to curriculum development already exists; in computer science CITIDEL is a repository of existing syllabi (http://www.citidel.org/) that enables designers of new courses to understand how others have approached the problem [23]. A community wiki was used in IS (http://blogsandwikis.bentley.edu/iscurriculum/) to help develop the curriculum dynamically [22]. A detailed account of a project to dynamically create and establish a Web Science curriculum were presented to the Web Science conference in 2011 [26]. The Web Science Curriculum Development project proposes a bottom up approach to drive curriculum definition, using the actual teaching materials collected in a community repository as the basis to iteratively negotiate and refine the definition of the curriculum. This is consistent with work by Cassells et al. on using a computing ontology [10]. Reservations voiced by Mitchel and Lutter [16] are to some extent answered by the findings of 
Dicheva and Dichev who argue for the strength of the repositoryled approach [11]. The approach of the Web Science Curriculum Development Project proposes a means to begin co-creating and defining the body of knowledge, and identifying the actual focus of real courses. That body of knowledge will be more detailed when there are more courses, more students and larger cohorts.

\section{FUTURE WEB SCIENCE CURRICULA}

More work is needed to agree whether Web Science has a place in the family of computing disciplines, and if so, at what level. An initial examination suggests that Web Science may have a place. Current practice shows far more postgraduate specialisms in Web Science than undergraduate. We might therefore expect the specification of a model curriculum for Web Science to follow the pattern established by information systems in their recent recommendations $[12,22]$ where the model for masters preceded that for undergraduates, but we might also usefully debate whether Web Science is an undergraduate topic. Three factors which may be influential in distinguishing degrees are i) emphasis on the mathematical and theoretical, often a strong signature in many European degrees; ii) early specialization in subject area often typical in courses derived from UK roots; iii) broad foundation with later specialization - more typical of North American models. These factors are likely to influence the curriculum content, but may also determine whether a subject is most commonly found at undergraduate or post-graduate level.

The introduction of Web Science into the computing curriculum would add further complexity to discussions on the place of computational thinking introduced by Wing in 2006 [27]. The definitions of Web Science make clear the need to differentiate between the science of the web, and the underlying methods tools and technologies so often manifested as components of the computer science and IT curricula. There are many emerging, perhaps transient specialisms or sub-fields for example forensic computing or cyber-security, often historical artifacts which are able to capture the imagination of potential students, but Web Science is more than a historical artifact. Web Science covers much ground that is beyond the traditional focus of computing disciplines, with attendant implications for teaching and curriculum. This inter-disciplinarity of Web Science raises issues of the relationship between epistemological paradigms, cognitive approaches, and practical application first noted by Biglan [9]. The contribution by Halford et al. in 'Manifesto for Web Science?' articulates some of these interdisciplinary challenges [15]. These perspectives are particularly relevant to the CC2005 listed 'performance capabilities of graduates'. Web Science graduates would expect to perform more strongly in Biglan's soft applied area - suggesting a need to nuance the theory versus application differentiation used in the CC2005 problem space definition.

Web Science has a particular role in preparing graduates for jobs which do not yet exist. Although we may not be able to predict future job titles, we might predict that understanding the science of the web could be a crucial for employees and researchers of the future. Familiarity with a discipline which continues to emerge new technological solutions, business models and to augment and evolve human and social interactions can enable graduates to have the capacity to respond to future change. Developing the knowledge, skills and understandings which are concomitant with Web Science will be a powerful personal resource. Web Science within computing might also shift the gender balance and total skill set of computing graduates, a change which would be most noticeable in computer science. Ongoing debate needs to be scheduled and we should seriously consider expanding our notions of the study of computing.

\section{ACKNOWLEDGMENTS}

We would like to thank participants in the Web Science Curriculum Development Project, participants in the Web Science curriculum workshops and reviewers for feedback. Frank McCown for comments the first draft and Hugh Davis for ongoing criticisms. Michalis Vafopoulos received assistance developing WSSC from Ioannis Antoniou and Anastasia Dimou, Aristotle University of Thessaloniki, George Metakides, University of Patras, Leslie Carr, University of Southampton, Jacek Kopecky, The Open University and Kieron O'Hara, Web Science Trust, UK

\section{REFERENCES}

[1] ACM/AIS/IEEE-CS Joint Task Force for Computing Curricula. 2005. Computing Curricula 2005: The Overview Report.

[2] ACM/IEEE-CS Joint Interim Review Task Force. 2008. Computer Science Curriculum 2008: An Interim Revision of CS 2001, Report from the Interim Review Task Force.

[3] ACM/IEEE-CS Joint Task Force on Computing Curricula. 2001. Computing Curricula 2001: Computer Science.

[4] Barabási, A.-L. and Albert, R. October 15, 19991999. Emergence of Scaling in Random Networks. Science, 286 (5439), 509-512.

[5] Berners-Lee, T. 2007 The Process of Designing Things in a Very Large Space: Keynote Presentation http://www.W3.org/2007/Talks/0509-www-Keynote-Tb1/. In Proceedings of the WWW2007, (Banff, Alberta, Canada).

[6] Berners-Lee, T. 2010. Long Live the Web: A Call for Continued Open Standards and Neutrality. Scientific American, November 222010.

[7] Berners-Lee, T., Hall, W., Hendler, J., Shadbolt, N. and Weitzner, D. J. 11 August 2006. Creating a Science of the Web. Science, 313 (5788), 769 - 771.

[8] Berners-Lee, T., Hall, W., Hendler, J. A., O'Hara, K., Shadbolt, N. and Weitzner, D. J. 2006. A Framework for Web Science. Foundations and Trends ${ }^{\circledR}$ in Web Science, 1 (1), $1: 130$.

[9] Biglan, A. 1973. Relationships between Subject Matter Characteristics and the Structure and Output of University Departments. Journal of Applied Psychology, 57 (3), 204213.

[10] Cassel, L. N., Davies, G., LeBlanc, R., Snyder, L. and Topi, H. June 23-27 2008. Using a Computing Ontology as a Foundation for Curriculum Development. In Proceedings of the SW-EL'08 Sixth International Workshop on Ontologies and Semantic Web for E-Learning in conjunction with ITS 2008 (Montreal, Canada).

[11] Dicheva, D. and Dichev, C. 2010. Finding Resources and Collaborators within Digital Collections. In Proceedings of the International Conference on Web Intelligence and Intelligent Agent Technology, (Toronto, Canada.).

[12] Gorgone, J. T., Gray, P., Stohr, E. A., Valacich, J. S. and Wigand, R. T. 2006. MSIS 2006: Model Curriculum and Guidelines for Graduate Degree Programs in Information Systems. SIGCSE Bulletin, 38 (2), 121-196.

[13] Halford, S., Pope, C. and Carr, L. April 26-27th, 2010, 2010. A Manifesto for Web Science? In Proceedings of the WebSci10: Extending the Frontiers of Society On-Line, (Raleigh, NC: US.).

[14] Hendler, J., Shadbolt, N., Hall, W., Berners-Lee, T. and Weitzner, D. 2008. Web Science: An Interdisciplinary 
Approach to Understanding the Web. Communications of the ACM, 51 (7), 60-69.

[15] Lunt, B. M., Ekstrom, J. J., Gorka, S., Hislop, G., Kamali, R., Lawson, E., LeBlanc, R., Miller, J. and Reichgelt, H. 2008. Information Technology 2008: Curriculum Guidelines for Undergraduate Degree Programs in Information Technology.

[16] Mitchell, S. M. and Lutters, W. G. 2006. Assessing the Value of Computer Science Course Material Repositories. In Proceedings of the The19th Conference on Software Engineering Education and Training Workshops

[17] Riera, D. 2009. Web Science: A New Computer-Related Curriculum. In Proceedings of the WebSci'09: Society OnLine, (Athens, Greece).

[18] Sahami, M., Aiken, A. and Zelenski, J. 2010. Expanding the Frontiers of Computer Science: Designing a Curriculum to Reflect a Diverse Field. In Proceedings of the 41st ACM technical symposium on Computer Science Education, (Milwaukee, Wisconsin, USA),47-51.

[19] Sahami, M., Guzdial, M., McGettrick, A. and Roach, S. 2011. Setting the Stage for Computing Curricula 2013: Computer Science -- Report from the ACM/IEEE-CS Joint Task Force. In Proceedings of the 42nd ACM Technical Symposium on Computer science education, (Dallas, TX).

[20] Shadbolt, N. and Berners-Lee, T. 2008. Web Science Emerges. Scientific American, 299 (4), 76.
[21] Shneiderman, B. 2007. Web Science: A Provocative Invitation to Computer Science. Communications of the $A C M, 50$ (6), 25-27.

[22] Topi, H., Valacich, J. S., Wright, R. T., Kaiser, K., Jay F Nunamaker, J., Sipior, J. C. and Gert Jan de Vreede. 2010. IS2010: Curriculum Guidelines for Undergraduate Degree Programs in Information Systems

[23] Tungare, M., Yu, X., Cameron, W., Teng, G., PérezQuiñones, M. A., Cassel, L., Fan, W. and Edward A. Fox. March 07-11 2007. Towards a Syllabus Repository for Computer Science Courses. In Proceedings of the 38th SIGCSE Technical Symposium on Computer Science Education, (Covington, Kentucky, USA ).

[24] Vafopoulos, M. Web Science Subject Categorization (WSSC) Web Science Trust http://webscience.org/2010/wssc.html

[25] Vafopoulos, M. May 16-18 2011. The Web Science Subject Categorization (WSSC). In Proceedings of the ACM WebSci '11, (Koblenz, Germany).

[26] White, S., Croitoru, M., Bazan, S., Cerri, S., Davis, H. C., Jonquet, C., Prini, G., Scharffe, F., Staab, S., Tiropanis, T. and Vafopoulos, M. May 16-18 2011. Negotiating the Web Science Curriculum Development through Shared Educational Artefacts. In Proceedings of the ACM WebSci '11, (Koblenz, Germany).

[27] Wing, J. M. 2006. Computational Thinking. Communications of the ACM, 49 (3), 33-35.

Table 1. An abridged representation of the Web Science Subject Categorization.

NB: The full version at http://webscience.org/2010/wssc.html also specifies level 3 headings

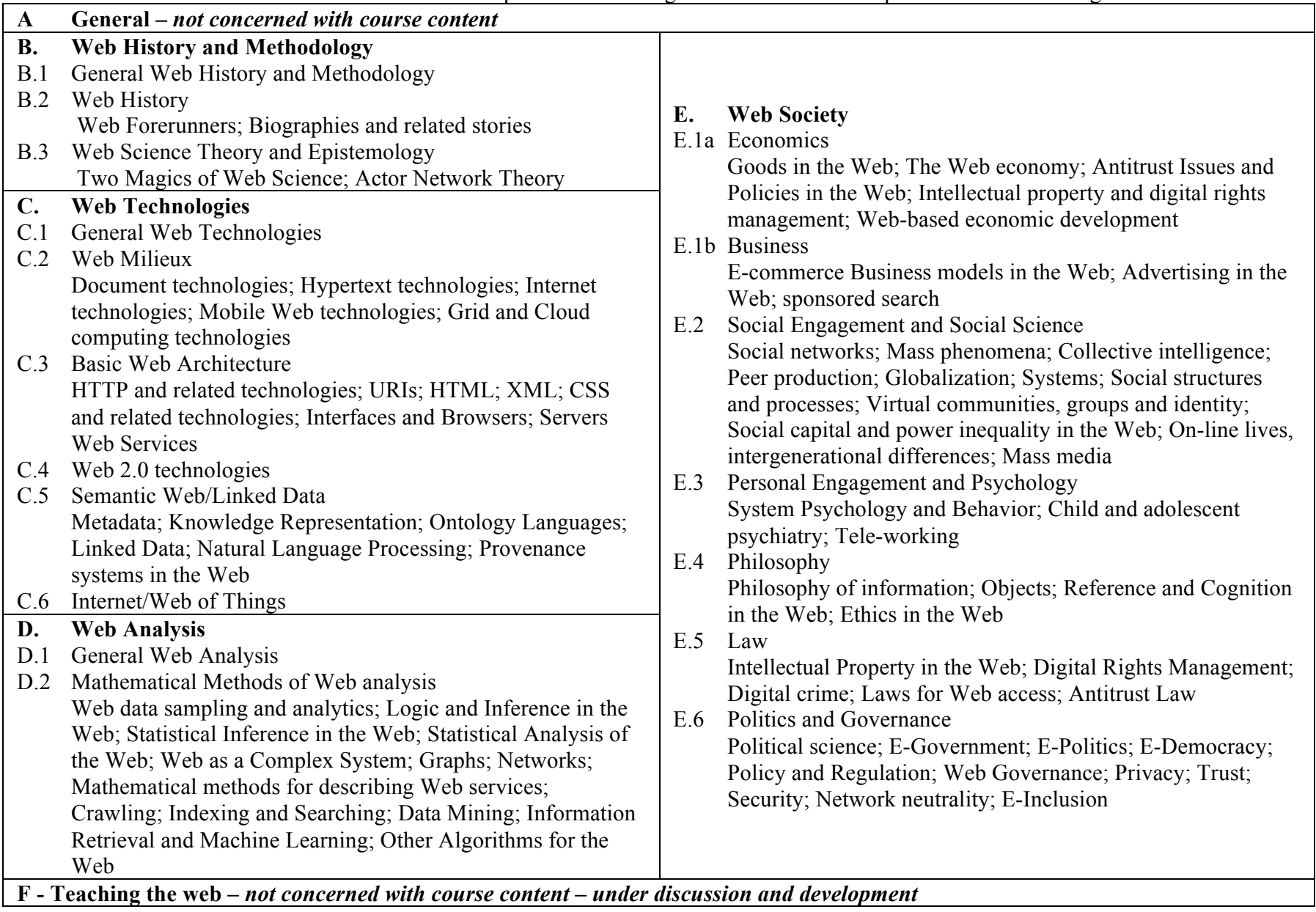

